\section{TON-UP EQUIPMENT}

\section{High Pressure Methods in Solid State Research \\ By C. C. Bradley. Pp. vii +176 . (Butterworths: London, December 1968.) $60 s$.}

Atтhough the first qualitative measurements of the effects of high pressure on materials go back as far as the eighteenth century, the major developments in pressure technology have occurred mainly during the past few decades. P. W. Bridgman invented techniques for the containment of hydrostatic pressures approaching 50 kilobars and quasihydrostatic pressures of more than 100 kilobars, and showed that the measurement of resistivities and compressibilities of materials under these conditions gave important information for the understanding of the nature of material at zero pressure. This stimulus led, in the fifties, to the remarkable expansion of the subject throughout Europe and the United States, until today the range of measurements under pressure is as wide as solid state physics itself. In his book, C. C. Bradley presents us with a survey of the advances in design of high pressure equipment that have occurred within this period.

The author has concentrated on equipment that is readily manufactured in the average laboratory workshop. The production of multianvil devices is, however, probably too ambitious for the normal university technical service, while on the other hand, some simpler anisotropic stress equipment is completely omitted. This is unfortunate, because the lifting of the degeneracy of a band edge in cubic material by uniaxial stress, for example, can be of crucial importance in the discovery of the basic electronic band structure.

The presentation is clear and attractive and the contents are up to date. The diagrams are well labelled, but more of them should include dimensions, a not unimportant consideration for the use of a book of this kind. In general, however, this inadequacy is compensated by the accompanying discussion. Bradley's book provides an excellent introduction to the techniques of high pressure experimentation for the newcomer to the field, yet undoubtedly it will exist as a convenient guide to the more experienced pressure worker.

\section{Neville Connell}

\section{BRAIN CHEMISTRY}

\section{Serotonin}

By Irvine H. Page. Pp. 143. (Year Book Medical Publishers: Chicago. Distributed in the UK by Wiley: Chichester, Sussex, February 1969.) 75s.

IRvine H. PAGE, in collaboration with Rapport and Green, suggested the identification of serotonin with 5-hydroxytryptamine in 1948. Since then, an enormous volume of original work and a number of reviews and monographs have appeared. Page himself has written two major reviews. In writing this small book he has made no attempt to be comprehensive but to present a personal view of developments in this field over the past twenty years, which will indicate the "trends and highlights so that a newcomer will not be overwhelmed by the thousands of papers already extant".

The first chapter deals with the biochemistry of 5 . hydroxytryptamine. The account of its synthesis and metabolism is marred for the newcomer by the lack of figures, but the section dealing with uptake by the tissues and release is more successful and a balanced picture is presented. There is also a clear and concise account of the effect of serotonin on carbohydrate metabolism in invertebrates.

A short chapter of ten pages entitled "Physiological
Aspects" discusses briefly the action on the vascular system, on which the author has himself worked extensively, on the gut and on temperature control. The account of the vascular actions is, as would be expected, clearly presented and here the personal approach is apparent, but scant justice is done to the very large body of work on the action of 5-hydroxytryptamine on smooth muscle and on temperature control. This chapter and the somewhat longer following chapter on the brain and its serotonin contain here and there sentences where excessive compression has resulted in statements which are inaccurate or incomprehensible.

The two final chapters deal with the part played by serotonin in the action of psychotropie drugs and in various disease states. This is a field where speculation is rife and much work needs to be done to clear up conflicting evidence. It is useful to have the mass of literature briefly summarized.

'The 365 references cover adequately the more important papers, and from the reviews cited, a reader should be able to find his way into the literature. The text contains far too many misprints and the index is poor.

R. S. Stacey

\section{REVIEW AT THE DOUBLE}

The Structure and Function of Nervous Tissue

Vol. 1: Structure 1. Edited by G. H. Bourne. Pp. xlv +542 . (Academic Press: New York and London, March 1969.) 261s $4 d$.

THIs is yet another of those collections of mini-reviews that seem to come in a never ending stream nowadays. "The first of a series to be published in rapid succession", the editor tells us in his preface. Speed is a dubious virtue and could well have been sacrificed in favour of a planned and coherent presentation (especially when the book costs so much). For one cannot escape the conclusion that the editor has not really done his job. It is not just that the same topic is covered several times by different authors, but that the accounts differ; neurofibrils, neurofilaments and neurotubules, for example, mean different things to four different authors. In most of the chapters there is thus much redundant material, fillings lacking in authority, that the conscientious editor would have chopped and replaced with a crossreference.

In the first of the eleven papers, Horridge deals with origins of the nervous system-physiology, pharmacology, coarse and fine structure. Horridge always stimulates but is often annoyingly cryptic. To be told that neurones are recognized in primitive animals because they look like nerve cells, doesn't really help. Also, phrases such as "the chemical stage of amplification" with reference to synaptic interaction will not endear him to the novice. He is wrong when he says no particular inclusions are found only in neurones. Examples are: the spine apparatus of the cerebral cortex, linked tubules in the axon hillock, and the membrane undercoating at initial segments and nodes of Ranvier.

Langman describes histogenesis of the central nervous system. This is a useful light microscopic account, but it suffers because of the author's lack of understanding of fine structure. Nowadays, light and electron microscopic observations are really inseparable.

Lumsden's chapter on nervous tissue in culture is the longest and least fortunate of the articles. Several of the figures have things wrong with them. For example, the double bar image in Fig. 16 is a desmosome not a synaptic contact; Fig. 32 has an obvious neurotubule labelled neurofilament; Fig. 24 is upside down, and so on. Lumsden has obviously had long experience of tissue culture with light microscopy but he seems regrettably out of his 